\title{
Anesthetic Management of Pheochromocytoma
}

\author{
Kattani Shyamprasad Amod ${ }^{1}$, Faizya Taskeen ${ }^{2}$, KT Venkatesh Murthy ${ }^{3}$, Hiremathada Sahajananda ${ }^{4}$
}

\begin{abstract}
Pheochromocytomas (PCCs) are rare neuroendocrine tumors originating from the chromaffin tissue. ${ }^{1}$ These tumors produce, store, and secrete catecholamines. Most PCCs produce both epinephrine and norepinephrine, with the percentage of secreted norepinephrine being greater than that secreted by the normal gland. ${ }^{2}$

The incidence of PCCs is 2 to 8 per 1 million populations per year. They are highly vascular and catecholamine-producing tumors. They are derived from the sympathetic or parasympathetic nervous system. It is estimated that $0.1 \%$ of all hypertensives may have neuroendocrine tumors like PCC. In these patients, usual presenting signs and symptoms are tachycardia, hypertension, etc., ${ }^{3}$ which are the result of sympathetic stimulation. The literature also shows a high prevalence of familial and extra adrenal tumors in patients carrying germline mutations in genes. ${ }^{1}$ It may be as high as 50\%. ${ }^{1}$ Surgery and anesthesia in these patients pose a high risk of cardiovascular complications from hypertensive crisis. Here, we report a case of PCC scheduled for surgical resection.
\end{abstract}

Keywords: Catecholamines, Hypertension, Hypertensive crises, Pheochromocytoma.

The Journal of Medical Sciences (2019): 10.5005/jp-journals-10045-00103

\section{INTRODUCTION}

Catecholamine-producing tumors which are derived from the sympathetic or parasympathetic nervous system are called pheochromocytomas (PCCs). ${ }^{3}$ Once diagnosed as PCCs, their removal can prevent lethal complications like hypertensive crises. Main aims of anesthetic management include proper preanesthetic checkup, intraoperative fluid management as well as management of complications like hypertension and posttumor removal hypotension. The chief presenting complaints are fluctuating blood pressure (BP), sweating, and palpitations. ${ }^{3}$ Catecholamine release, if not controlled, can result in severe hypertension, cerebrovascular, and myocardial complications. ${ }^{3}$ This patient group poses a challenge to anesthesiologists in managing them intraoperatively as well as in ICU.

Here, we report a case of PCC for surgical resection. We discuss the preoperative evaluation, intraoperative management, and postoperative care of patients who will undergo resection of PCC.

\section{Perioperative Management}

Thorough preoperative assessments of these patients result in successful perioperative management. Roizen et al. have proposed a set of criteria to objectively gauge the efficacy of adequate preoperative alpha blockade, which are as follows:

- No-in-hospital BP of $>160 / 90 \mathrm{~mm} \mathrm{Hg}$ for 24 hours prior to surgery

- No orthostatic hypotension with BP $<80 / 45 \mathrm{~mm} \mathrm{Hg}$

- No ST or T wave changes for 1-week prior to surgery

- Not more than five premature ventricular contractions per minute.

\section{Case Report}

A 32-year-old female patient came with a history of left flank pain, dizziness, headache, and occasional palpitations since 1 month. The patient is a known case of hypothyroidism (8 years) on treatment with tab. thyronorm $100 \mu \mathrm{g}$ and hypertension (5 years on tab. telmisartan $40 \mathrm{mg}$ + hydrochlorothiazide $12.5 \mathrm{mg}$ ). Patient's CT scan revealed a well-defined homogeneous lesion in \begin{tabular}{l}
\hline${ }^{1-4}$ Department of Anaesthesiology and Critical Care, RajaRajeswari \\
Medical College \& Hospital, Bengaluru, Karnataka, India \\
Corresponding Author: Kattani Shyamprasad Amod, Department \\
of Anesthesiology and Critical Care, RajaRajeswari Medical College \& \\
Hospital, Bengaluru, Karnataka, India, Phone: +91 9538626747; e-mail: \\
amod.shreyu@gmail.com \\
How to cite this article: Amod KS, Taskeen F, Murthy KTV, Sahajananda \\
H. Anesthetic Management of Pheochromocytoma.J Med Sci 2019;5(1): \\
11-13. \\
Source of interest: Nil \\
Conflict of interest: None
\end{tabular}

the retroperitoneum on the left side anterior to left renal vessels, adherent to the body of pancreas abutting the small bowel loops. The patient was diagnosed as a case of left-sided paraganglioma/ extra-adrenal PCC. The patient was admitted at the Department of urology and worked up for the same.

Her investigations showed normal 24 hours urine metanephrines and vanillyl mandelic acid levels in her urine were high, 44.12/24 hours (normal <13.6). Fasting blood sugar (FBS) was 154, post prandial blood glucose (PPBS) was 273 , and $\mathrm{HbA1c}$ was 7.5 , rest of her investigations were normal.

The patient had BP readings of $140 / 90 \mathrm{~mm} \mathrm{Hg}$ to $160 / 90 \mathrm{~mm}$ $\mathrm{Hg}$ after admission. The patient was posted for tumor excision.

The patient was a $70 \mathrm{~kg}$ female with a height of $105 \mathrm{~cm}$ and a body mass index (BMI) of 29. She was obese, with short neck and airway of mallampati grade II. Her BP was 170/110 $\mathrm{mm} \mathrm{Hg}$, and heart rate (HR) was $95 \mathrm{bpm}$. The patient was advised to stop all antihypertensives and started on tab. phenoxybenzamine $10 \mathrm{mg}$ tid. The patient was started on inj. human actrapid according to the sliding scale and general random blood sugar (GRBS) was monitored every 4 hours. Preop orders included nil per orally (NPO)-6 hours, tab. alprazolam $25 \mathrm{mg}$ for anxiolysis, inj. ranitidine and ondansetron, tab. thyronorm $100 \mu \mathrm{g}$ on the morning of surgery, and skipping morning insulin dose.

The patient was continuously monitored in ICU-her BP and HR readings are shown in Table 1.

(0) The Author(s). 2019 Open Access This article is distributed under the terms of the Creative Commons Attribution 4.0 International License (https://creativecommons. org/licenses/by-nc/4.0/), which permits unrestricted use, distribution, and non-commercial reproduction in any medium, provided you give appropriate credit to the original author(s) and the source, provide a link to the Creative Commons license, and indicate if changes were made. The Creative Commons Public Domain Dedication waiver (http://creativecommons.org/publicdomain/zero/1.0/) applies to the data made available in this article, unless otherwise stated. 
Table 1: Monitoring of patient in ICU

\begin{tabular}{lll}
\hline Time & $B P(\mathrm{~mm} \mathrm{Hg})$ & $H R(\mathrm{bpm})$ \\
\hline 4 PM (day before surgery) & $170 / 110$ & 95 \\
6 PM (day before surgery) & $166 / 100$ & 96 \\
8 PM (day before surgery) & $160 / 100$ & 95 \\
12 AM (day before surgery) & $156 / 100$ & 94 \\
4 AM (day of surgery) & $140 / 100$ & 90 \\
6 AM (day of surgery) & $156 / 100$ & 90 \\
8 AM (day of surgery) & $148 / 94$ & 90 \\
9 AM (day of surgery) & $160 / 100$ & 93 \\
\hline
\end{tabular}

The patient's vitals before shifting to OR were as follows: BP 170/100 $\mathrm{mm} \mathrm{Hg}, \mathrm{HR} 96 \mathrm{bpm}, \mathrm{FBS}-151 \mathrm{mg} / \mathrm{dL}$, and serum electrolytes were normal.

\section{Anesthetic Management}

Preoperative counseling of the patient and attenders was done. Operation room was prepared and all drugs required including inotropes, vasodilators, emergency drugs, vasopressors, antiarrythmics, blood, and blood products were arranged. Preoperative consent was obtained.

Electrocardiogram (ECG), oxygensaturation, noninvasive blood pressure (NIBP), temperature, and urine output were monitored and two-wide bore IV cannulas (18 G and $20 \mathrm{G}$ ) were secured and IV infusion of crystalloids was started. End tidal $\mathrm{CO}_{2}$ monitoring was commenced after intubation under all aseptic precautionthe right-hand radial artery was cannulated with a $20 \mathrm{G}$ cannula; arterial BP monitoring was instituted. Patient's vitals were: arterial BP 180/100 mm Hg (Fig. 1), HR 100 bpm, and $\mathrm{SPO}_{2}$ 100\%.

Injection Esmolol $30 \mathrm{mg}$ in $100 \mathrm{~mL}$ normal saline (NS) was started IV, 10 minutes before intubation. Injection sodium nitroprusside infusion $3 \mathrm{~mL} /$ hour was started in view of arterial BP readings of 200/120 $\mathrm{mm} \mathrm{Hg}$. Inj. midazolam $2 \mathrm{mg} \mathrm{IV} \mathrm{and} \mathrm{inj.} \mathrm{fentanyl}$ $100 \mu \mathrm{g}$ were given as premedication. After 15 minutes, the vitals were: BP 140/100 mm Hg and HR 101 bpm.

The patient was preoxygenated with $100 \%$ oxygen, induced with inj. propofol $100 \mathrm{mg}$, sevoflurane + oxygen, inj. rocuronium $30 \mathrm{mg}$ was given, the patient intubated with a cuffed endotracheal tube of size 7.0, the bilateral air entry was checked, and the tube was fixed at $19 \mathrm{~cm}$ : BP 150/100 $\mathrm{mm} \mathrm{Hg}$ and HR $118 \mathrm{bpm}$. The patient

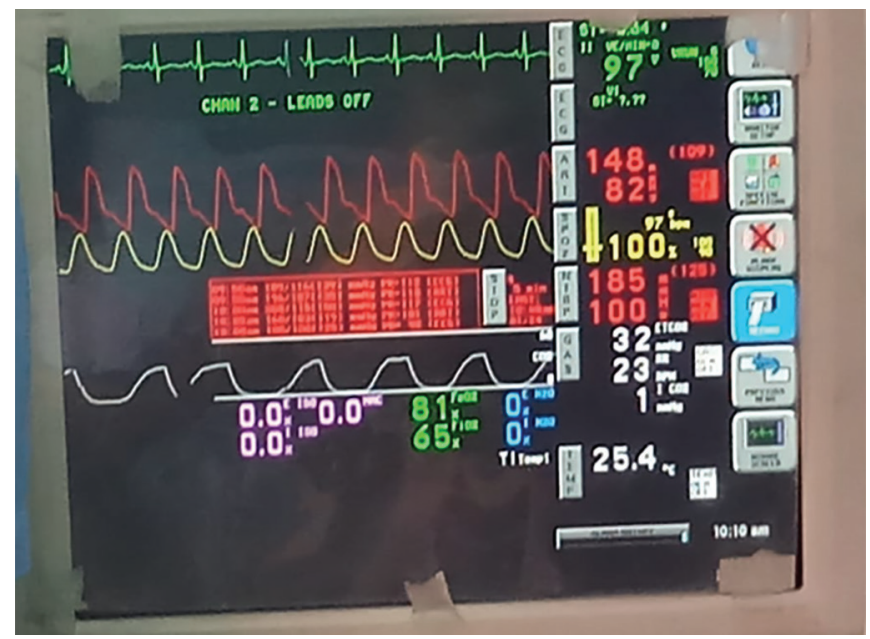

Fig. 1: Baseline vitals

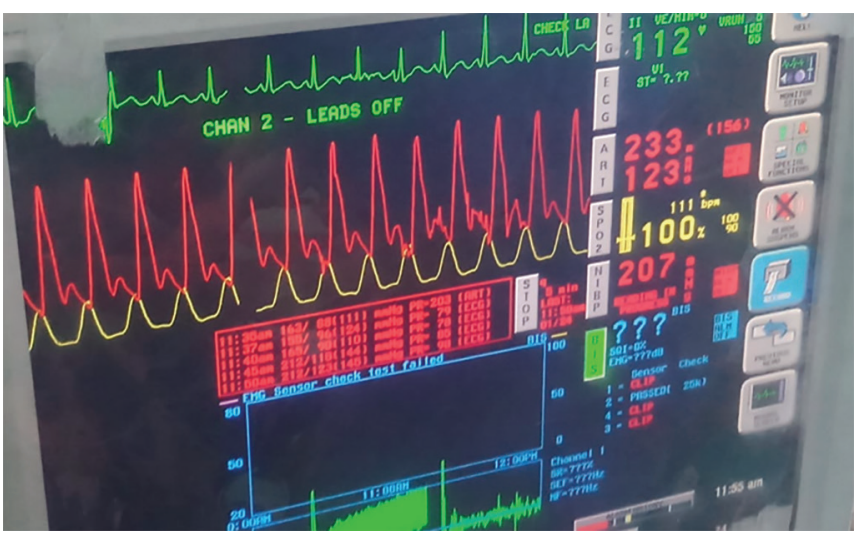

Fig. 2: Hypertensive response to stimulation

was maintained with $\mathrm{O}_{2}+\mathrm{N}_{2} \mathrm{O}+$ isoflurane $1 \%$ and intermittent doses of inj. vecuronium $0.5 \mathrm{mg}$. Injection paracetamol $1 \mathrm{~g}$ was administered IV as a part of multimodal analgesia. Under all aseptic precautions, the right subclavian central line was secured. The patient was then turned to the right lateral position and a thoracic epidural catheter was placed between T7 and T8 vertebrae and secured. The patient was then positioned for surgery in the right lateral position with adequate padding. Baseline BP was $124 / 67 \mathrm{~mm} \mathrm{Hg}$ with a HR of $69 \mathrm{bpm}$ before surgical incision. After 5 minutes of incision, BP increased to $170 / 100 \mathrm{~mm} \mathrm{Hg}$ and HR was $85 \mathrm{bpm}$. Injection sodium nitroprusside infusion increased to $5 \mathrm{~mL} /$ hour and isoflurane was increased to $1.2 \%$, inj. magnesium sulfate $1 \mathrm{~g}$ in $100 \mathrm{~mL}$ NS slow IV started as a membrane stabilizer to prevent arrhythmias. When surgeons started handling the tumor, BP shot up to $233 / 117 \mathrm{~mm} \mathrm{Hg}$ (Fig. 2), 200/118 mm Hg, and HR $103 \mathrm{bpm}$. Injection nitroglycerin infusion started at $2.5 \mathrm{~mL} /$ hour. Five minutes later, BP was 180/88 mm Hg and HR was $104 \mathrm{bpm}$. When surgeons excised the tumor out (Fig. 3), the BP dropped to $57 / 39 \mathrm{~mm} \mathrm{Hg}$ with a HR of $144 \mathrm{bpm}$. Injections sodium nitroprusside and nitroglycerin were stopped. Injection noradrenaline was started at $5 \mathrm{~mL} /$ hour $(0.08 \mathrm{mg} / \mathrm{mL})$, inj. phenylephrine $30 \mu \mathrm{g}-$ 2 bolus doses and inj. mephentermine $6 \mathrm{mg}-2$ bolus doses were administered. Isoflurane reduced to $0.6 \%$ MAC. Injection fentanyl $50 \mu \mathrm{g}$ was administered after tumor excision. Injection dexamethasone $8 \mathrm{mg}$ and inj. hydrocortisone $100 \mathrm{mg}$ were also administered.

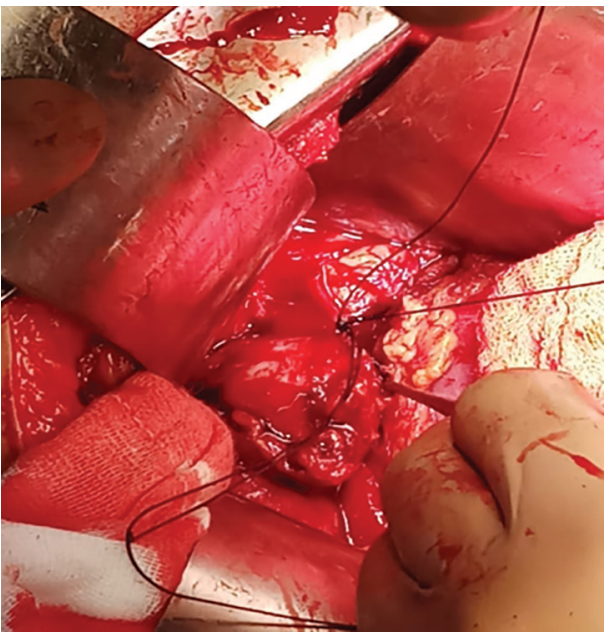

Fig. 3: Exicision of tumor 
Injection noradrenaline infusion was continued at $3 \mathrm{~mL} /$ hour. Random blood sugar (RBS) estimation was done which was $20 \mathrm{mg} / \mathrm{dL}$. It was corrected with $25 \%$ dextrose and maintained with dextrose in normal saline. After 20 minutes, repeated RBS showed $214 \mathrm{mg} / \mathrm{dL}$. During closure, BP increased to 200/100 mm Hg and the HR was $118 \mathrm{bpm}$, following which epidural was activated with $6 \mathrm{~mL}$ of $0.2 \%$ ropivacaine with $25 \mu \mathrm{g}$ of fentanyl. BP got stabilized at $150 / 74 \mathrm{~mm} \mathrm{Hg}$ and the HR was $110 \mathrm{bpm}$. Injection noradrenaline infusion was continued. Arterial blood gas (ABG) analysis was done which was satisfactory. Before extubation, inj. Esmolol $10 \mathrm{mg}$ slow IV was administered.

The patient was extubated after complete neuromuscular blockade reversal with inj. neostigmine $2.5 \mathrm{mg}$ and glycopyrrolate $0.5 \mathrm{mg}$. After the extubation, BP was $118 / 70 \mathrm{~mm} \mathrm{Hg}$, with an HR of $98 \mathrm{bpm}$. The patient had received 4 pints of Ringer's lactate, 3 pints of $0.9 \%$ saline, and 1 pint of dextrose in normal saline (DNS). Blood loss was minimal. The patient was shifted to surgical intensive care unit (SICU). One hour post-surgery, BP was 90/60 mm Hg, inj. noradrenaline infusion continued at $3 \mathrm{~mL} /$ hour. Twenty-four hours post-surgery, BP was $110 / 70 \mathrm{~mm} \mathrm{Hg}$ following which noradrenaline infusion was stopped. The patient was doing well. Seventy-two hours post-surgery, the patient had a high BP of $170 / 110 \mathrm{~mm} \mathrm{Hg}$ following which tab. Prazosin $2.5 \mathrm{mg}$ and tab. Metoprolol $50 \mathrm{mg}$ were started orally. The patient was discharged after the BP was stabilized.

\section{Discussion}

A majority of PCCs secrete mainly norepinephrine, sometimes paroxysmal but usually sustained and often in huge quantities. The majority of patients with PCC present with sustained severe hypertension. ${ }^{5}$ Released norepinephrine causes vasoconstriction in arteriolar and venous beds, thereby decreasing the circulating blood volume. PCCs are usually diagnosed and confirmed by raised urinary catecholamine and vanillylmandelic acid (VMA) in 24 hours urine samples. After the diagnosis, the tumor is localized accurately by computerized tomography (CT) scan, magnetic resonance imaging (MRI), and iodine-131-meta-iodobenzylguanidine imaging (MIBG) scans. ${ }^{6,7}$

Preoperative optimization helps in preventing the wide variation in arterial BP during the intraoperative period. This is achieved by antiadrenergic drugs, i.e., alpha $(\alpha)$ and beta $(\beta)$ blockers.
The sympathetic blockade is achieved first by an $\alpha$ adrenergic blocker followed by an $\alpha-\beta$ blocker. Alpha blockade results in vasodilatation and tachycardia which is controlled by beta blockers. If beta blockade is achieved first, then there may be unopposed vasoconstriction in skeletal muscles causing hypertension. Twenty-four hours ambulatory BP monitoring should show a BP of 140/90 mm of $\mathrm{Hg}$ and a HR of less than $100 \mathrm{bpm}^{8}$ And no more than five premature ventricular contractions per minute. Four lying and standing BP should show a postural drop up to but not less than $80 / 45 \mathrm{~mm} \mathrm{Hg}$ in the standing position. ${ }^{4}$ More drops indicate inadequate hydration. ECG should be free of ST changes for at least 2 weeks. ${ }^{8}$ Mortality is due to ignoring subtle changes of cardiomyopathy.

\section{Conclusion}

Patients with PCC are at a significant risk of major adverse cardiac complications in the perioperative period. Successful management requires careful preoperative optimization, meticulous intraoperative planning, and hemodynamic management. All patients need to be monitored vigilantly in the postoperative period given the high-risk of complications.

\section{References}

1. Ramakrishna $\mathrm{H}$. Pheochromocytoma resection: current concepts in anesthetic management. J Anaesthesiol, Clin Pharmacol 2015 Jul;31(3):317. DOI: 10.4103/0970-9185.161665.

2. Barash textbook clinical anesthesia, 7th ed. Wolters Kluwer India Private Limited, 1 December 2017; pp.1339-1342.

3. Suryawanshi C, Thatte WS, et al. Anesthetic management of a missed pheochromocytoma during exploratory laparotomy. Anaesth, Pain Intensive Care 2019 Feb 3:296-298.

4. Roizen MF. A prospective randomized trial of four anesthetic techniques for resection of pheochromocytoma. Anesthesiology 1982;57:A43.

5. Basu M, Gupta SD, et al. Anaesthetic management of bilateral phaeochromocytoma in a young female patient. Indian J Anaesth 2007 May 1;51(3):237.

6. Prys-Roberts C. Phaeochromocytoma-recent progress in its management. Br J Anaesth 2000 Jul 1;85(1):44-57.

7. Gupta P, Gogia AR, et al. Anaesthetic management of bilateral phaeochromocytoma in a child-a case report. Indian J Anaesth 2005 Jan 1;49(1):54-55. 